\title{
Avaliação da qualidade de potabilidade da água subterrânea em áreas rurais no município de Humaitá/AM
}

O objetivo desta pesquisa foi avaliar as características físicas, químicas e microbiológicas, da água subterrânea dos poços de abastecimento das comunidades rurais do município de Humaitá (AM) - em terras firmes (Ipixuna e Realidade) e em várzea (Paraíso Grande) - visando fornecer dados como subsídio para segurança hídrica e comparar com os padrões de potabilidade. Foram realizadas duas coletas, uma no período de seca, em agosto de 2017, e outra no período de chuva, em março de 2018. Foram analisados parâmetros físicos (temperatura, cor, condutividade, turbidez e sólidos totais dissolvidos), químicos ( $\mathrm{pH}$, alcalinidade, dureza, cloreto, nitrito, nitrato, ferro, manganês e sulfato) e microbiológicos (coliformes termotolerantes e Escherichia coli). Os resultados apresentaram valores inferiores aos limites estabelecidos pela Portaria de Consolidação № 5 do Ministério da Saúde, exceto o parâmetro cor da amostra da comunidade rural do Paraíso Grande e o parâmetro $\mathrm{pH}$, sendo inferior em todas as comunidades. Considera-se que a composição da formação de depósitos aluvionares que possui a presença de ferro e matéria orgânica, tenha alterado a cor da água da comunidade Paraíso Grande. Por fim, os poços nas áreas de terra firme apresentaram uma qualidade melhor da água subterrânea do que os poços da área de várzea, provavelmente pela característica geológica.

Palavras-chave: Água de poços; Qualidade da água; Segurança Hídrica; Terra Firme; Várzea.

\section{Evaluation of the potability quality of groundwater in rural areas in the municipality of Humaitá/AM}

\begin{abstract}
The objective of this research was to evaluate the physical, chemical and biological characteristics of groundwater from the wells of rural communities in the municipality of Humaitá (AM) - in terra firme (Ipixuna and Realidade) and várzea (Paraíso Grande) - in order to provide data as a subsidy for water security and compare with potability standards. Two collections were carried out in the dry season, in August 2017, and another one in the rainy season, in March 2018. The analyzed parameters were physical (temperature, color, conductivity, turbidity and total dissolved solids), chemical ( $\mathrm{pH}$, alkalinity, hardness, chloride, nitrite, nitrate, iron, manganese and sulfate) and microbiological (thermotolerant coliforms and Escherichia coli). The results presented values lower than the limits established by Ministry of Health Consolidation Ordinance No. 5 (BRAZIL, 2017), except the color parameter of the samplhe of the rural community of Paraíso Grande and lower $\mathrm{pH}$ in all communities. The characteristic of the formation of alluvial deposits that has is its characteristic the presence of iron and organic matter, probably changed the water color of the community Paraíso Grande. The wells in the terra firme areas presented a better groundwater quality than the floodplain area, probably due to the geological feature.
\end{abstract}

Keywords: Well Water; Water Quality; Hydric Security; Terra Firme; Várzea.

Topic: Administração Pública Ambiental

Reviewed anonymously in the process of blind peer.
Received: 02/01/2021

Approved: 28/01/2021
Laura Almeida Ferreira (iD)

Universidade Federal do Amazonas, Brasil http://lattes.cnpq.br/1130543242547263 http://orcid.org/0000-0002-3260-2079

lauraalmeidaferreira@hotmail.com

Elizabeth Tavares Pimentel

Universidade Federal do Amazonas, Brasil http://lattes.cnpq.br/8948618145123019

http://orcid.org/0000-0002-2615-2956

bethfisica@hotmail.com

Rafael Bel Prestes da Silva (iD)

Universidade Federal de Santa Maria, Brasil

http://lattes.cnpq.br/9796106286658874

http://orcid.org/0000-0003-3317-3955

rafael.bel.silva@seducam.pro.br

\author{
Aldecy de Almeida Santos (iD \\ Universidade Federal de Mato Grosso, Brasil \\ http://lattes.cnpq.br/3224921282419849 \\ http://orcid.org/0000-0003-4361-307X \\ aldecy allmeida@yahoo.com.br
}

Referencing this:

FERREIRA, L. A.; PIMENTEL, E. T.; SILVA, R. B. P.; SANTOS, A. A.. Avaliação da qualidade de potabilidade da água subterrânea em áreas rurais no município de Humaitá/AM. Revista lbero Americana de Ciências Ambientais, v.12, n.1, p.721-729, 2021. DOI: http://doi.org/10.6008/CBPC2179-6858.2021.001.0058 


\section{INTRODUÇÃO}

A água subterrânea é um importante recurso natural que serve como fonte confiável de água potável para muitas pessoas em todo o mundo, especialmente nos países em desenvolvimento (SAANA et al., 2016). No Brasil, segundo Castro (2012) "70\% dos recursos hídricos concentra-se na região Norte, dando uma percepção de abundância". Esse número expressivo causa na população da região Norte do país, a ilusão de uma infinita reserva hídrica e de que a escassez de água é uma particularidade restrita às regiões áridas.

As populações amazônicas que habitam as várzeas, invariavelmente, fixam-se às margens dos cursos de águas. Na várzea, a vida se move com o ciclo das águas, que sobem e descem, inundam e secam, abundam e escasseiam (AZEVEDO, 2006).

De acordo com Horbe et al. (2013) "as águas do rio Madeira são classificadas como brancas, bicabornatadas-cálcicas, têm pH entre 5 e 6, e transporta elevada carga de material em suspensão". Essas características induzem a população de várzea a assumir um comportamento de risco ao consumi-la. Sendo assim, é necessário o tratamento da água para adequar aos padrões de potabilidade exigidos pela legislação vigente.

Diferente do regime de várzea, caracterizado pelo ritmo das águas (enchente e vazante), a terra firme obedece ao ciclo anual imposta pelas chuvas (ALBUQUERQUE, 2016). As áreas de terra firme são áreas não inundáveis que muitas vezes não possuem águas superficiais (igarapés, lagos e rios) próximas às comunidades rurais gerando a escassez de água.

Neste contexto, as águas subterrâneas geralmente são utilizadas tradicionalmente para abastecer as comunidades rurais em áreas de várzea e terra firme para o consumo humano, pela facilidade de obtenção. Deste modo, a falta de um programa de monitoramento da qualidade das águas subterrâneas nestas comunidades rurais prejudica a preservação e conservação dos recursos hídricos subterrâneos e gera risco a saúde pública.

Sendo assim, o objetivo desta pesquisa trata-se de avaliar as características físicas, químicas e biológicas da água subterrânea dos poços de abastecimento das comunidades rurais do município de Humaitá (AM), em terra firme e em várzea, através da comparação com os padrões de potabilidade.

\section{METODOLOGIA}

O município de Humaitá está situado no sul do Estado do Amazonas e pertence à microrregião do Madeira. As comunidades rurais estudadas, pertencentes à cidade de Humaitá, foram Paraíso Grande $\left(7^{\circ} 31^{\prime}\right.$ $53,6^{\prime \prime}$ S e $62^{\circ} 59^{\prime} 40,9^{\prime \prime}$ W), Ipixuna $\left(07^{\circ} 31^{\prime} 27,9^{\prime \prime}\right.$ S e $63^{\circ} 20^{\prime} 48,8^{\prime \prime}$ W) e Realidade $\left(6^{\circ} 58^{\prime} 47,7^{\prime \prime}\right.$ S e $63^{\circ} 05^{\prime}$ $53,3^{\prime \prime}$ W), como ilustrado na Figura 1.

As comunidades do Paraíso Grande, Ipixuna e Realidade possuem precipitação média anual de 2.200 e $2.800 \mathrm{~mm}$, o clima da região está classificado, pelo método de Köppen, como tipo Am (chuvas do tipo monção), que apresenta um período seco de pequena duração, de junho até outubro, com temperaturas médias anuais variando entre de 25 a 27 ㄷ e com umidade relativa do ar bastante elevada, variando de 85 
a 90\%, possuindo altitude média de 90 m acima do nível do mar (BRASIL, 1978; EMBRAPA, 1997).

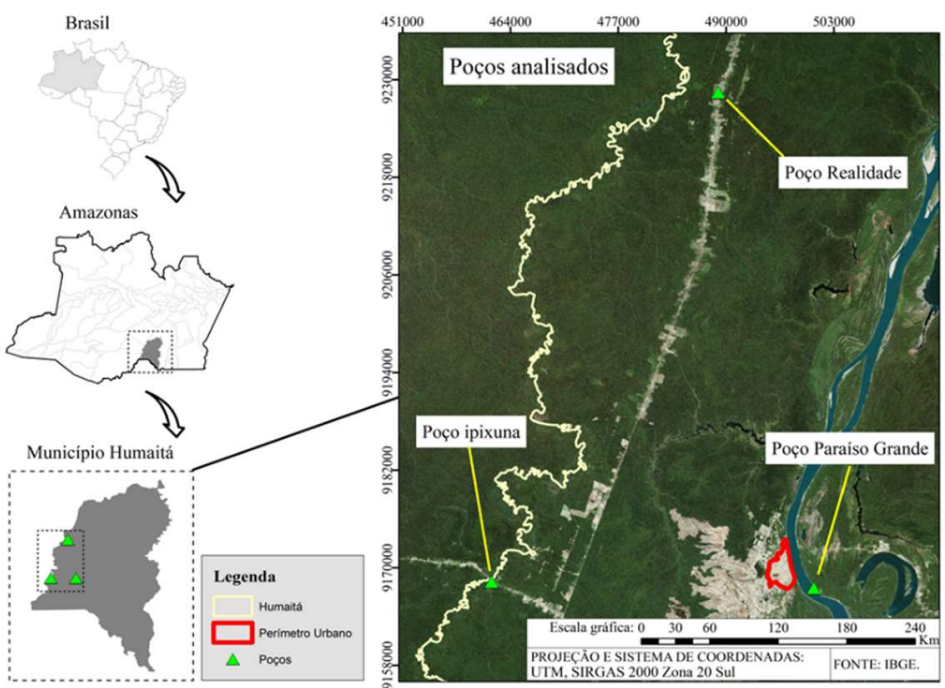

Figura 1: Mapa de localização das comunidades rurais no município de Humaitá-AM.

A geologia desta região é formada por materiais do Holoceno chamados de Aluviões Atuais provenientes de deposições fluviais (BRASIL, 1978). Os solos da região de Humaitá-AM são classificados como Latossolos, Argissolos, Plintossolos, Gleissolos, Espodossolos, Neossolos e Cambissolos trazendo consigo uma vegetação característica de Floresta Tropical Densa, com a presença de árvores multiestratificadas entre 20 e $50 \mathrm{~m}$ de altura (ZEE-AM, 2008; CAMPOS, 2012; OLIVEIRA et al., 2016).

As coletas para o monitoramento da qualidade da água dos poços nas áreas rurais aconteceram em duas etapas, no mês de agosto de 2018 , no período de seca (época de vazante) e no mês de maio período de chuva (época de enchente).

As análises de temperatura, condutividade e $\mathrm{pH}$ foram realizadas in loco. As coletas para as análises bacteriológicas foram as primeiras a serem realizadas e, em frasco estéreis de $540 \mathrm{~mL}$. As amostras de água para análises físicas e químicas foram coletadas em recipiente de $500 \mathrm{~mL}$ na boca do poço, em triplicata, acondicionadas em recipientes apropriados, preservadas e refrigeradas durante o transporte ao laboratório e realizadas de acordo com padrões da CETESB (1988). A Tabela 1 apresenta os parâmetros e métodos utilizados nas amostragens da qualidade da água.

Tabela 1: Parâmetros e métodos utilizados nas análises físicas, químicas e microbiológicas dos pontos de amostragem.

\begin{tabular}{|c|c|c|c|c|c|}
\hline PARÂMETROS & MÉTODOS & & \multicolumn{3}{|l|}{ NORMA E /OU PROCEDIMENTO } \\
\hline Temperatura & Método Eletrométrico & & \multicolumn{3}{|l|}{ SMEWW, 22a Ed. Método 2550 B } \\
\hline Cor aparente & $\begin{array}{l}\text { Método Espectrofotométrico } \\
\text { Cobalto). }\end{array}$ & (Platino- & \multicolumn{3}{|l|}{ SMEWW, 22a Ed. Método 2120 B } \\
\hline Turbidez & Método Nefelométrico. & & \multicolumn{3}{|l|}{ SMEWW, 22a Ed. Método 2130 B } \\
\hline Sólidos Totais Dissolvidos & Gravimétrico & & \multicolumn{3}{|l|}{ SMEWW, 22a Edição, Método 2540 C } \\
\hline Condutividade & Condutivímetro & & \multicolumn{3}{|l|}{ SMEWW, 22a Ed. Método 2510 B } \\
\hline $\mathrm{pH}$ & Método eletrométrico & & \multicolumn{3}{|l|}{ SMEWW, 22a Ed. Método 4500 B } \\
\hline Alcalinidade & Método Titulométrico & & \multicolumn{3}{|l|}{ SMEWW, 22a Ed. Método 2320 B } \\
\hline Dureza & Método Titulométrico do EDTA-Na & & \multicolumn{3}{|l|}{ SMEWW, 22a Ed. Método $2340 \mathrm{C}$} \\
\hline Cloreto & Mohr & & \multicolumn{3}{|l|}{ SMEWW, 22a Ed. Método 4500 B } \\
\hline Ferro & Método Colorimétrico - Fenantrolina & & $\begin{array}{l}\text { SMEWW, 22a } \\
\text { (Determinação). }\end{array}$ & 3111 & B \\
\hline Manganês & Colorimétrico - Persulfato & & $\begin{array}{l}\text { SMEWW, 22a } \\
\text { (Determinação). }\end{array}$ & 3111 & B \\
\hline Nitrato & Método Eletrodo Íon Seletivo & & \multicolumn{3}{|l|}{ SMEWW, 22a Ed. Método 4110 B } \\
\hline
\end{tabular}




$\begin{array}{lll}\text { Nitrito } & \text { Método Eletrodo Íon Seletivo } & \text { SMEWW, 22a Ed. Método 4500 B } \\ \text { Sulfato } & \text { Espectrofotométrico } & \text { SMEWW, 22a Ed. Método 4110 B } \\ \text { Coliformes } & \text { NMP (Substrato enzimático) } & \text { SMEWW, 22a Ed. Método 9223 } \\ \text { termotolerantes } & \text { NMP (Substrato enzimático) } & \\ \text { Coliformes totais } & \text { SMEWW, 22a Ed. Método 9223 }\end{array}$

Fonte: APHA et al. (2012).

\section{RESULTADOS E DISCUSSÃO}

\section{Parâmetros físicos}

A Tabela 2 apresenta os resultados dos valores de temperatura das águas de poços nas comunidades rurais, separados por período de seca e de chuva.

Tabela 2: Resultados das temperaturas $\mathrm{T}\left({ }^{\circ} \mathrm{C}\right)$, do ar e da água dos poços das comunidades rurais no período de seca e de chuva.

\begin{tabular}{lllll}
\hline Período de seca & & Paraíso Grande & Ipixuna & Realidade \\
\hline $\mathrm{T}\left({ }^{\circ} \mathrm{C}\right)$ & Ar & $27,13 \pm 0,12$ & $28,07 \pm 0,31$ & $26,90 \pm 0,45$ \\
& Água & $27,97 \pm 0,12$ & $26,50 \pm 0,08$ & $26,53 \pm 0,12$ \\
V.M.P & & - & - & - \\
\hline Período de Chuva & & & $30,53 \pm 0,74$ & $31,33 \pm 0,17$ \\
\hline $\mathrm{T}\left({ }^{\circ} \mathrm{C}\right)$ & $\mathrm{Ar}$ & $31,27 \pm 0,12$ & $31,47 \pm 0,61$ & $31,73 \pm 0,09$ \\
& Água & $32,47 \pm 0,12$ & - & - \\
\hline
\end{tabular}

V.M.P: valor máximo permitido

De acordo com os resultados obtidos a temperatura média da água dos poços na comunidade Paraíso Grande e de todas as comunidades no período de chuva apresentaram valores superiores à temperatura média do ar. Estas variações de temperatura são características de aquíferos freáticos pouco profundos, onde a temperatura é um pouco superior à da superfície (FEITOSA et al., 2000). No período de seca nas comunidades Ipixuna e Realidade as médias da temperatura da água foram inferiores à temperatura média do ar com amplitude térmica de $0,37^{\circ} \mathrm{C}$ a $1,67{ }^{\circ} \mathrm{C}$, dentro da faixa de 1 a $2{ }^{\circ} \mathrm{C}$, encontrados em águas subterrâneas. Os conhecimentos da variação desses resultados são de grande importância, pois a temperatura influencia os processos biológicos, reações químicas e bioquímicas, bem como a solubilidade dos gases dissolvidos e sais minerais na água (MACEDO, 2004). A legislação de potabilidade não estabelece temperatura máxima para água de consumo conforme a PC № 5 de 2017.

Os valores obtidos também são compatíveis com valores de temperatura em subsuperfície da região, conforme consta no trabalho de Pimentel et al. (2010). Isso comprova que a temperatura da água nos poços tem consequência direta da radiação solar incidente na superfície, e pode explicar porque no período de chuva foram obtidos valores maiores do que no período de seca. Parte da energia armazenada durante todo período de seca é liberada no período de chuva aumentando a temperatura da água dos poços. Na Tabela 3 apresentam-se os resultados dos parâmetros físicos: cor, turbidez, condutividade e sólidos totais dissolvidos obtidos no período de estudo.

Os valores de cor nas comunidades do Ipixuna e Realidade foram "não detectados (ND)", no período de seca e no período chuvoso, valores bem inferiores a 15 uH, exigido pela legislação PC № 5 de 2017. Portanto, a sazonalidade não apresentou efeito regular entre as estações seca e chuvosa nas áreas de terra firme. Na comunidade do Paraíso Grande os valores de cor foram superiores a legislação PC № 5 de 2017, 
em ambos os períodos de seca e chuva devido à característica do solo e formação geológica de depósito aluvionares com presença de ferro e matéria orgânica e inorgânica dissolvida, alterando assim a cor da água.

Tabela 3: Resultados de cor, turbidez, condutividade elétrica (EC) e sólidos totais dissolvidos (STD) da água dos poços das comunidades rurais, nos períodos de seca e de chuva.

\begin{tabular}{lllll}
\hline Parâmetro & Período & Paraíso Grande & Ipixuna & Realidade \\
\hline \multirow{2}{*}{ Cor (mgPtCo/L) } & seca & $19,00 \pm 0,82$ & ND & ND \\
\hline V.M.P & chuva & $20,03 \pm 0,12$ & ND & ND \\
\hline \multirow{2}{*}{ Turbidez (NTU) } & & $\mathbf{1 5 , 0 0}$ & $\mathbf{1 5 , 0 0}$ & $\mathbf{1 5 , 0 0}$ \\
\hline V.M.P & seca & $5,00 \pm 0,10$ & 0,00 & 0,00 \\
\hline \multirow{2}{*}{ CE(mg/L) } & chuva & 0,00 & 0,00 & 0,00 \\
\hline V.M.P & & $\mathbf{5 , 0 0}$ & $\mathbf{5 , 0 0}$ & $\mathbf{5 , 0 0}$ \\
\hline \multirow{2}{*}{ STD (mg/L) } & seca & $25,67 \pm 0,47$ & $7,33 \pm 1,89$ & $15,33 \pm 0,47$ \\
\hline V.M.P & chuva & $19,00 \pm 0,10$ & $6,00 \pm 0,82$ & $9,67 \pm 0,47$ \\
\hline
\end{tabular}

Os resultados de turbidez apresentaram valores inferiores a 5 NTU, limite estabelecido pela PC № 5 , nas comunidades Ipixuna e Realidade em áreas de terra firme. No entanto, a comunidade Paraíso Grande apresentou valores de turbidez superiores ao limite da referida portaria. De acordo com observações realizadas em campo durante a coleta, verificou-se, que o aspecto da água era amarelada e com algumas partículas em suspensão, provavelmente, devido à presença de silte, argila, ferro, matéria orgânica e inorgânica.

Outra justificativa é a construção de poços inadequados e fora dos padrões, muitos deles sem o préfiltro que retém os sólidos mais grosseiros e o filtro que retém os sólidos mais finos. Observou-se também a falta de impermeabilização nos furos necessária para maior segurança, conforme consta no trabalho de Kuhn et al. (2015).

As condutividades elétricas (CE) apresentaram valores inferiores a $30 \mu \mathrm{S} / \mathrm{cm}$ indicando pequena quantidade de sais dissolvidos e ionizados que conduzem a corrente elétrica, e pode estar relacionado provavelmente com a presença das concentrações dos íons cloretos $\left(\mathrm{Cl}^{-}\right)$, cálcio $\left(\mathrm{Ca}^{+2}\right)$ e magnésio $\left(\mathrm{Mg}^{+2}\right)$ e outros íons dissolvidos na água, no Paraíso Grande foram obtidos valores elevados de CE, pela presença de concentrações de cloretos elevadas comparadas aos outros poços.

Os sólidos totais dissolvidos (STD) apresentaram resultados inferiores a $1000 \mathrm{mg} / \mathrm{L}$, estabelecido pela PC № 5. Esses valores provavelmente estão ocorrendo devido ao maior volume de água presente na região na época da chuva, na qual acarreta mais material e diferente tipo de constituintes iônicos. Além disso, o aumento da infiltração da água no solo contribui para um maior fluxo subterrâneo e influência nos sólidos totais aumentando sua concentração.

\section{Parâmetros químicos}

A Tabela 4 apresenta os resultados dos parâmetros químicos de pH, alcalinidade, dureza, cloreto da água dos poços das comunidades rurais. 
Tabela 4: Resultados dos parâmetros químicos: pH, alcalinidade (Alc.), dureza, cloreto, Ferro, Manganês, Nitrito, Nitrato e Sulfato da água das comunidades rurais no período de seca e de chuva.

\begin{tabular}{|c|c|c|c|c|}
\hline Parâmetro & Período & Paraíso Grande & Ipixuna & Realidade \\
\hline \multirow{2}{*}{$\mathrm{pH}$} & seca & $5,70-6,20$ & $4,80-5,10$ & $4,90-5,50$ \\
\hline & chuva & $5,80-6,30$ & $4,90-5,30$ & $5,20-5,70$ \\
\hline V.M.P & & $6,00-9,50$ & $6,00-9,50$ & $6,00-9,50$ \\
\hline \multirow{2}{*}{ Alc. (mg/L) } & seca & $9,43 \pm 0,41$ & $4,70 \pm 0,67$ & $5,17 \pm 0,61$ \\
\hline & chuva & $7,78 \pm 1,88$ & $4,53 \pm 0,25$ & $4,93 \pm 0,25$ \\
\hline V.M.P & & - & - & - \\
\hline \multirow{2}{*}{ Dureza (mg/L) } & seca & $14,00 \pm 1,63$ & $4,00 \pm 1,63$ & $5,33 \pm 2,49$ \\
\hline & chuva & $9,00 \pm 0,82$ & $2,33 \pm 1,70$ & $5,00 \pm 2,94$ \\
\hline \multirow[t]{2}{*}{ V.M.P } & & - & - & - \\
\hline & seca & $7,00 \pm 2,45$ & $3,00 \pm 2,45$ & $6,67 \pm 0,94$ \\
\hline Cloreto (mg/L) & chuva & $4,67 \pm 1,25$ & $2,00 \pm 1,63$ & $3,33 \pm 2,49$ \\
\hline \multirow[t]{2}{*}{ V.M.P } & & - & - & - \\
\hline & seca & $0,15 \pm 0,12$ & 0,00 & 0,00 \\
\hline Ferro $(\mathrm{mg} / \mathrm{L})$ & chuva & $0,12 \pm 0,11$ & 0,00 & 0,00 \\
\hline \multirow[t]{2}{*}{ V.M.P } & & 0,3 & 0,3 & 0,3 \\
\hline & seca & 0,00 & 0,00 & 0,00 \\
\hline Manganês (mg/L) & chuva & 0,00 & 0,00 & 0,00 \\
\hline V.M.P & & 0,1 & 0,1 & 0,1 \\
\hline \multirow{2}{*}{ Nitrito (mg/L) } & seca & 0,01 & 0,00 & 0,00 \\
\hline & chuva & 0,00 & 0,00 & 0,00 \\
\hline \multirow[t]{2}{*}{ V.M.P } & & 1 & 1 & 1 \\
\hline & seca & $6,00 \pm 0,45$ & $0,30 \pm 0,42$ & $0,33 \pm 0,47$ \\
\hline Nitrato $(\mathrm{mg} / \mathrm{L})$ & chuva & 0,00 & 0,00 & 0,00 \\
\hline \multirow[t]{2}{*}{ V.M.P } & & 0,1 & 0,1 & 0,1 \\
\hline & seca & $4,00 \pm 2,94$ & $0,33 \pm 0,47$ & $0,33 \pm 0,47$ \\
\hline Sulfato (mg/L) & chuva & $1,67 \pm 2,36$ & 0,00 & 0,00 \\
\hline V.M.P & & 250 & 250 & 250 \\
\hline
\end{tabular}

Os resultados obtidos de pH caracterizaram a água como sendo de ácida a levemente ácida, provavelmente, devido ao gás carbônico dissolvido e da alcalinidade e reflexo da lixiviação do solo e rochas. O valor mínimo foi registrado no período de seca de 4,80 e o máximo de 6,30 e no período chuvoso, observando que os valores elevados de pH ocorrem no período chuvoso. Feitosa et al. (2000) destacam que "a maioria das águas subterrâneas tem pH entre 5,5 e 8,5".

Nas comunidades do Ipixuna e Realidade as águas apresentaram valores de $\mathrm{pH}$ que oscilaram entre 4,60 a 5,70, dentro da faixa de 4,5 a 5,8 encontrados em aquíferos freáticos no estado do Amazonas (CPRM, 2010). A comunidade Paraíso Grande apresentou um pH levemente ácido, provavelmente devido à característica de terra de várzea, e influenciado pelo Rio Madeira, diferentemente das comunidades que estão situadas em terra firme como Ipixuna.

Os resultados de $\mathrm{pH}$ apresentaram valores inferiores ao limite estabelecido pela PC № 5 (BRASIL, 2017), que recomenda uma faixa de 6,0 a 9,5, exceto nas maiorias das amostras de seca e chuva da comunidade Paraíso Grande. Valores de pH baixo, fora das faixas recomendadas, podem favorecer a alteração do sabor da água e contribuir para corrosão dos sistemas de distribuição de água.

Os valores obtidos de alcalinidade das amostras de água nos poços foram reduzidos em todos os poços, ocorrendo pouca mudança no $\mathrm{pH}$ em ambos os períodos. Foram observadas à presença apenas da alcalinidade de bicarbonatos, uma vez que as formas de alcalinidade das águas é função de seu pH, e estes se encontram dentro da faixa de $\mathrm{pH} 4,4-8,3$.

Todas as amostras no período de seca e de chuva apresentaram resultados de dureza muito abaixo 
do limite estabelecido, na faixa de 0,00 a $16,00 \mathrm{mg} \mathrm{CaCO}_{3} / \mathrm{L}$, sendo considerada uma água mole. $O$ padrão de potabilidade estabelece valor máximo de $500 \mathrm{mg} \mathrm{CaCO}_{3} / \mathrm{L}$. A dureza em águas é um indicativo da concentração, sobretudo, de cátions de cálcio $\left(\mathrm{Ca}^{2+}\right)$ e magnésio $\left(\mathrm{Mg}^{2+}\right)$ (TARTARI et al., 2014).

Por não apresentar significado sanitário, seu inconveniente é de natureza econômica por reduzir a formação de espuma (resistência à saponificação), elevando o consumo de sabões e xampus, causar sabor desagradável e podendo provocar incrustações nas tubulações de abastecimento de águas domésticas (LIBÂNIO, 2010).

Os valores obtidos para as concentrações de íons cloreto presentes nas amostras apresentaram valores inferiores a $250 \mathrm{mg} / \mathrm{L}$, estabelecido pela PC № 5 de 2017, do Ministério da Saúde para águas destinadas ao abastecimento público (BRASIL, 2017). Esse resultado mostra que os valores desse parâmetro contribuem para a boa qualidade da água, uma vez que os maiores problemas relacionados ao uso de águas é o alto índice de salinidade, que é provocada pelas altas concentrações de íons presentes.

Observando os resultados obtidos na análise dos metais em todos os pontos e os limites estabelecidos pela legislação, verifica-se que as amostras apresentaram quantidades bem abaixo do valor máximo permitido (BRASIL, 2017). Para ferro, tem-se o valor de $0,29 \mathrm{mg} / \mathrm{L}$ como concentração mais elevada, detectada no Paraíso Grande no período de seca. A análise de manganês apresentou resultado apenas em uma amostra no Paraíso Grande no período de seca com valores bem inferiores ao limite máximo permitido pela legislação, que é de 0,1 mg/L.

Os valores de nitrito e nitrato obtidos em todos os poços foram inferiores ao estabelecido pela PC № 5 de 2017, do Ministério da Saúde. Altas concentrações de nitrato na água estão relacionadas à falta de sistema de esgotamento sanitário, sendo comum em outras regiões do país. Nas águas subterrâneas, os nitratos ocorrem em teores geralmente abaixo de $5 \mathrm{mg} / \mathrm{L}$ (ARAUJO et al., 2013).

Os valores de sulfato das águas subterrâneas dos poços das comunidades apresentaram teores inferiores ao limite permitido pela legislação $(250 \mathrm{mg} / \mathrm{L})$, variando de $0 \mathrm{mg} / \mathrm{L}$ até $10 \mathrm{mg} / \mathrm{L}$. Em águas naturais, as concentrações de $\mathrm{SO}_{4}{ }^{2-}$ variam, em geral, entre 0 a $7 \mathrm{mg} / \mathrm{L}$. As variações naturais de qualidade das águas subterrâneas são pequenas, assim, características extremas ou diferentes daquelas esperadas indicam a presença de situações anômalas como corpos de minério, metamorfismo de rochas ou ação antrópica (PARRON et al., 2011).

\section{Parâmetros microbiológicos}

A Tabela 5 apresenta os resultados de coliformes totais e Escherichia coli da água dos poços das comunidades rurais. Neste estudo em todas as amostras das águas de poços os resultados não apresentaram coliformes totais e Escherichia coli, em conformidade com a PC № 5 de 2017 do Ministério da Saúde (BRASIL, 2017), nos dois períodos de seca e chuva. A Escherichia coli é um micro-organismo considerado como o mais importante indicador de poluição fecal das águas, portanto, de risco à saúde quando se consome água em que ele está presente. De modo geral, a utilização de água subterrânea como fonte alternativa pela população rural a expõe a doenças de veiculação hídrica, pois não há conhecimento dessas populações sobre 
a falta de qualidade sanitária da água consumida sem nenhum tipo de tratamento associado à falsa ideia de que a água subterrânea seja potável, além da falta de condições sanitárias satisfatórias na zona rural (QUEIROZ et al., 2002).

Tabela 5: Resultados dos parâmetros microbiológicos: coliformes totais (Col. Totais) e Escherichia coli (E. Coli) das comunidades rurais no período de seca e de chuva.

\begin{tabular}{|c|c|c|c|c|c|c|}
\hline & $\begin{array}{l}\text { Col. Totais } \\
\text { (NMP/100ml) }\end{array}$ & & & $\begin{array}{l}\text { E. Coli } \\
\text { (NMP/100ml) }\end{array}$ & & \\
\hline & Paraíso Grande & Ipixuna & Realidade & Paraiso Grande & Ipixuna & Realidade \\
\hline Período seca & Ausente & Ausente & Ausente & Ausente & Ausente & Ausente \\
\hline V.M.P (PC no 05) & Ausente & Ausente & Ausente & Ausente & Ausente & Ausente \\
\hline Período de chuva & Ausente & Ausente & Ausente & Ausente & Ausente & Ausente \\
\hline V.M.P (PC no 05) & Ausente & Ausente & Ausente & Ausente & Ausente & Ausente \\
\hline
\end{tabular}

\section{CONCLUSÕES}

Os valores médios obtidos dos parâmetros físicos, químicos e microbiológicos das águas subterrâneas apresentaram-se adequados para o consumo humano, de acordo com a Portaria de Consolidação n. 5 de 28 de setembro de 2017, do Ministério da Saúde, exceto o parâmetro pH em que os valores estão abaixo do permitido em todos os poços, e a cor na comunidade Paraíso Grande.

A característica da formação de depósitos aluvionares que possui na sua composição a presença de ferro e matéria orgânica, provavelmente alterou a cor da água da comunidade Paraíso Grande.

Os poços nas áreas de terra firme apresentaram uma qualidade melhor da água subterrânea em relação à área de várzea, provavelmente pela característica geológica.

\section{REFERÊNCIAS}

ALBUQUERQUE, J. D. R.. Agricultura familiar: análise comparativa da produção de hortaliças na várzea e terra firme de Parintins, AM. Dissertação (Mestrado em Agronomia Tropical) - Universidade Federal do Amazonas, Manaus, 2016.

APHA; AWWA; WEF. American Public Health Association; American Water Works Association; World Economic Forum. Standard Methods for examination of water and wastewater. 22 ed. Washington APHA, 2012.

ARAUJO, C. F.; HIPÓLITO, J. R.; WAICHMAN, A. V.. Avaliação da qualidade da água de poço. Rev. Inst. Adolfo Lutz, São Paulo, v.72, n.1, p.53-58, 2013.

AZEVEDO, R. P.. Uso de água subterrânea em sistema de abastecimento público de comunidades na várzea da Amazônia central. Acta Amazônica, v.36, n.3, p.313-320, 2006.

BRASIL. Ministério da Saúde. Portaria Consolidação n.05, de 28 de setembro de 2017. Brasília: MS, 2017

BRASIL. Ministério das Minas e Energia. Projeto Radam Brasil, folha SB. 20, Purus. Rio de Janeiro: MME, 1978.

CAMPOS, M. C. C.. Caracterização e gênese de solos em diferentes ambientes fisiográficos na região Sul do Amazonas. Goiânia: PUC Goiás, 2012.
CASTRO, C. N.. Gestão das Águas: Experiências Internacional e Brasileira. Texto para Discussão 1744. Brasília: IPEA, 2012.

CETESB. Companhia Ambiental do Estado de São Paulo. Guia de coleta e preservação de amostras de água. São Paulo: CETESB, 1988.

CPRM. Companhia de Pesquisa de Recursos Minerais. Boletim n. 04/2010: Monitoramento hidrológico. Manaus: CPRM, 2010

EMBRAPA. Empresa Brasileira de Pesquisa Agropecuária. Estudo de viabilidade agrícola de cerrados do Amazonas. Brasília: EMBRAPA, 1997.

FEITOSA, F. A. C.; MANOEL FILHO, J.. Hidrogeologia: conceitos e aplicações. 2 ed. Fortaleza: CPRM, 2000.

HORBE, A. M. C.; QUEIROZ, M. M. A.; MOURA, C. A. V.; TORO, M. A. G.. Geoquímica das águas do médio e baixo rio Madeira e seus principais tributários - Amazonas - Brasil. Acta Amazônica, v.43, n.4, p.489-504, 2013.

KUHN, M. R.; ZART, N.; OLIVEIRA, E. C.. Avaliação físicoquímica e microbiológica da qualidade das águas dos poços artesianos que abastecem o distrito de boa vista, no município de Triunfo, RS. Revista destaques acadêmicos, v.7, n.4, p.132-140, 2015. 
LIBÂNIO, M.. Fundamentos de qualidade e tratamento de água. 3 ed. Campinas: Átomo, 2010.

OLIVEIRA, B. O. S.; TUCCI, C. A. F.; NEVES JUNIOR, A. F.; SANTOS, A. A.. Avaliação dos solos e das águas nas áreas de influência de disposição de resíduos sólidos urbanos de Humaitá, Amazonas. Revista Engenharia Sanitária Ambiental, v.21, n.3, p.593-601, 2016.

PARRON, L. M.; MUNIZ, D. H. F.; PEREIRA, C. M.. Manual de procedimentos de amostragem e análise físico-química da água. Colombo: Embrapa Florestas, 2011.

PIMENTEL, E. T.; ARAUJO, R. L. C.; MONTEIRO, I. B.; SILVA, R. M.. Estudo de Geotermia Rasa na cidade de Humaitá, AM. Revista Brasileira de Geofísica, v.28, n.4, p.563-578, 2010.
QUEIROZ, M. F.; CARDOSO, M. C. S.; SANTANA, E. M.; GOMES, A. B.; RIQUE, S. M. N.; LOPES, C. M.. A qualidade da água de consumo humano e as doenças diarreicas agudas no município de Cabo de Santo Agostinho, PE. Brazilian Journal of Epidemiology, p.456-462, 2002.

TARTARI, R.; NASCIMENTO, I. C. L.. Avaliação da qualidade físico-química da água em uma escola localizada ao sul do Amazonas: proposta de ensino e conscientização ambiental. EDUCAmazônia: Educação Sociedade e Meio Ambiente, v.12, n.1, p.127-146, 2014.

ZEE-AM. Zoneamento Ecológico Econômico do Sul-Sudeste do Amazonas. Zoneamento ecológico econômico do SulSudeste do Amazonas. Manaus: IPAAM, 2008.

A CBPC - Companhia Brasileira de Produção Científica (CNPJ: 11.221.422/0001-03) detém os direitos materiais desta publicação. Os direitos referem-se à publicação do trabalho em qualquer parte do mundo, incluindo os direitos às renovações, expansões e disseminações da contribuição, bem como outros direitos subsidiários. Todos os trabalhos publicados eletronicamente poderão posteriormente ser publicados em coletâneas impressas sob coordenação da Sustenere Publishing, da Companhia Brasileira de Produção Científica e seus parceiros autorizados. Os (as) autores (as) preservam os direitos autorais, mas não têm permissão para a publicação da contribuição em outro meio, impresso ou digital, em português ou em tradução. 